Diabetologia $11,175-180$ (1975)

(c) by Springer-Verlag 1975

\title{
Effect of Cephalic Glucose Infusion on Insulin Secretion
}

\author{
R. A. Chieri,* J. M. S. Farina, J. Halperin and J. C. Basabe* \\ Institute of Physiology, Buenos Aires Medical School, Argentina \\ Received: June 14, 1974, and in revised form: January 8, 1975
}

\begin{abstract}
Sumary. The continous infusion of glucose $(1 \mathrm{mg} / \mathrm{kg} / \mathrm{min})$ via the carotid artery in anesthetized dogs produces a biphasic pattern of insulin secretion. The first peak reaches a maximum $3 \mathrm{~min}$ after glucose infusion and drops to basal level at $7 \mathrm{~min}$. As long as the glucose infusion persists a slow and mantained increase in insulin level in the pancreaticoduodenal vein can be observed. The same amount of glucose infused in the general circulation via the jugular vein provoked a different pattern of insulin secretion. Cerebral glucose infusion to vagotomized dogs also produced a two phase response in insulin secretion, but the levels reached in the first
\end{abstract}

phase were lower that those observed in the normal dogs. The infusion of glucose, via the jugular vein, in vagotomized dogs, failed to induce any change in plasma insulin levels. Our data suggest that a glucose load to the brain induces pancreatic insulin secretion mediated partially by the vagus nerves. These results are also compatible with the hypothesis that a humoral factor could be involved in the pancreatic response.

Key-words: Insulin secretion; vagus nerves; cephalic glucose infusion.
The role of the nervous system in the control of blood sugar level was recognized many years ago [2]. Sympathetic and adrenal function were implicated in the neural mechanism of hyperglycemia [4]. The physiological role played by the vagus nerves on the control of blood sugar level has been a conflicting issue. Although early workers reported enhanced insulin secretion associated with vagal stimulation [5, 8], the fact that the transplanted pancreas was able to maintain blood sugar homeostasis, diminished the importance of vagal control of insulin secretion [9, 13]. Stimulation of the vagus nerve has been reported to produce no changes [17] or increase in plasma immunoreactive insulin $[6,8,14,18]$.

The hypothalamus is also involved in the maintenance of blood sugar homeostatis.Rats with electrolytic lesions of the ventromedial region have improved glucose tolerance tests and increased sensitivity to insulin [21]. The improvement of the diabetic glucose tolerance of the sand rat after hypothalamic injury has also been described [3]. Furthermore, androgenized female rats developed diabetes sooner than the normal animals when subjected to partial pancreatectomy [7]. In guinea pigs, electrolytic lesions of the anterior and middle hypothalamus were followed by insulin hypersensitivity and lower fasting blood sugar levels [1]. Evidence for an insulin-sensitive receptor in the central nervous system [19] and for a central adrenergic regulation of insulin has also been reported [20].

\footnotetext{
* Members of Carrera del Investigador Científico, Consejo Nacional de Investigaciones Científicas y Técnicas, Argentina.
}

The present experiment was designed to help resolve the unsettled question concerning the role played by the central nervous system on the control of insulin secretion.

\section{Material and Methods}

Normal and vagotomized mongrel dogs of either sex, weighing between 17 to $20 \mathrm{~kg}$ were used. Bilateral vagotomy was accomplished at the intra-thoracic portion of the nerve at the level of the lower third of the esophagus. A period of ten days elapsed between surgery and the experimental procedure, to avoid the influence of stress.

\section{Experimental Procedure}

After eighteen hours of fasting the normal or vagotomized dogs were anesthetized by intravenous injection of nembutal $(33 \mathrm{mg} / \mathrm{kg})$ and submitted to the following surgical procedure: the pyloric region was approached through a medial laparatomy, a polyethylene cathether was placed in the pancreaticoduodenal vein via the right gastroepiploic vein. Both carotid arteries were canulated with a polyethylene tube through the lower thyroid artery. A fourth polyethylene tube was placed in a branch of the femoral artery.

After surgery the animals were allowed to rest for one hour to stabilize the basal condition. They were kept under nembutal anesthesia during the experimental period. 
At 0 time, blood samples were withdrawn from the pancreatico-duodenal vein and the femoral artery. Glucose or saline infusion was then started immediately, via the carotid artery or the jugular vein (depending on the group studied) at a dose of $1 \mathrm{mg} / \mathrm{min} /$ $\mathrm{kg}$ and continously maintained during one hour using a Harvard infusion pump. Blood samples from the pancreatico-duodenal vein and the femoral artery were taken at different times for insulin and glucose determination. Blood sugar was determined by the Somogyi Nelson method [16]. Plasma immunoreactive insulin was determined by the Herbert method [10].

The following groups were studied: 1 . Normal dogs infused with glucose $(0.34 \mathrm{mM})$ via carotid artery. 2. Normal dogs infused with sodium chloride $(0.34$ $\mathrm{mM}$ ) via carotid artery. 3. Normal dogs infused with sodium chloride $(0.17 \mathrm{mM})$ via carotid artery. 4 . Normal dogs infused with glucose $(0.34 \mathrm{mM})$ via jugular vein. 5. Normal dogs infused with sodium chloride $(0.34 \mathrm{mM})$ via jugular vein. 6 . Vagotomized dogs infused with glucose $(0.34 \mathrm{mM})$ via carotid artery. 7 . Vagotomized dogs infused with glucose $(0.34 \mathrm{mM})$ via jugular vein.

Statistical analysis was performed by the $t$ test. The values observed in each group during the infusion period was compared with its basal values.

\section{Results}

\section{Effect of Glucose Infusion into the Carotid Artery on Insulin Secretion}

The infusion of glucose into the carotid artery produced an increase in the insulin levels in the pancreatico-duodenal vein with a two-phase pattern of secretion. The first peak reached a maximum $3 \mathrm{~min}$ after glucose infusion and at $7 \mathrm{~min}$ dropped to near basal level. As long as glucose infusion persisted, a slow and maintained increase in insulin levels in the pancreatico-duodenal vein was observed. The insulin output reached a maximum at $40 \mathrm{~min}$. From 60 to 90 minutes, the time after the glucose infusion was stopped, plasma insulin dropped to basal levels. Plasma insulin values in the general circulation began to increase from $7 \mathrm{~min}$ until the end of the experiment; no two-phase pattern was observed and the values were lower than those observed in the pancretico-duodenal vein. Blood sugar levels remained unchanged throughout the entire experiment (Table 1).

The same amount of glucose infused in the general circulation via the jugular vein provoked a different pattern of insulin secretion. A slow but steady increase in plasma insulin was detected in the pancreatico- duodenal vein from 15 to $60 \mathrm{~min}$; from 60 to $90 \mathrm{~min}$ plasma insulin levels dropped to basal values.

Plasma insulin and blood sugar levels determined in the general circulation (femoral artery) showed no change, remaining at basal values during the entire experiment (Table 1).

The infusion of isotonic $(0.17 \mathrm{mM})$ or hypertonic $(0.34 \mathrm{mM})$ sodium chloride solution into the carotid artery did not provoke any pancreatic response. Similarly, the infusion of isotonic sodium chloride solution in the general circulation did not modify the glycemia and insulinaemia (Table 2).

\section{Effect of Vagotomy on the Response to Cerebral Glucose Infusion}

Cerebral glucose infusion to vagotomized dogs changed the pancreatic response previously described in normal dogs. A two-phase response was also observed in insulin secretion but the levels reached in the first phase were statistically lower than the observed in the normals $(p<0.05$ at 3 and $5 \mathrm{~min}$ ). In the second phase, although the values obtained were not statistically different a tendency to a diminished insulin secretion was observed. No changes in plasma insulin levels were detected in blood from the femoral artery, probably as a consequence of the diminished insulin output. The blood sugar level remains unchanged throughout the experiment (Table 1).

The infusion of glucose via the jugular vein in vagotomized dogs failed to provoke any changes in plasma insulin levels and glycemia (Table 1).

As a summary of the results obtained, in Fig. 1 the values of plasma insulin levels determined in the pancreatico-duodenal vein for the different groups studied are shown.

\section{Discussion}

The present experiment demonstrates that glucose infusion to the brain, via the carotid artery, elicits a pancreatic response shortly after the beginning of infusion, which lasted as long as infusion was maintained. This effect was not caused by alterations in the circulating volume or in the osmolarity of blood reaching the central nervous system, since isotonic or hypertonic sodium chloride infusion failed to provoke any changes in the plasma immunoreactive insulin levels. Likewise, the modifications observed were not a consequence of the glucose acting at other levels of the body, since jugular infusion of glucose at the same dose was unable to provoke the same pancreatic response. Vagotomy diminished the pancreatic insulin release triggered by the infusion of glucose to the 


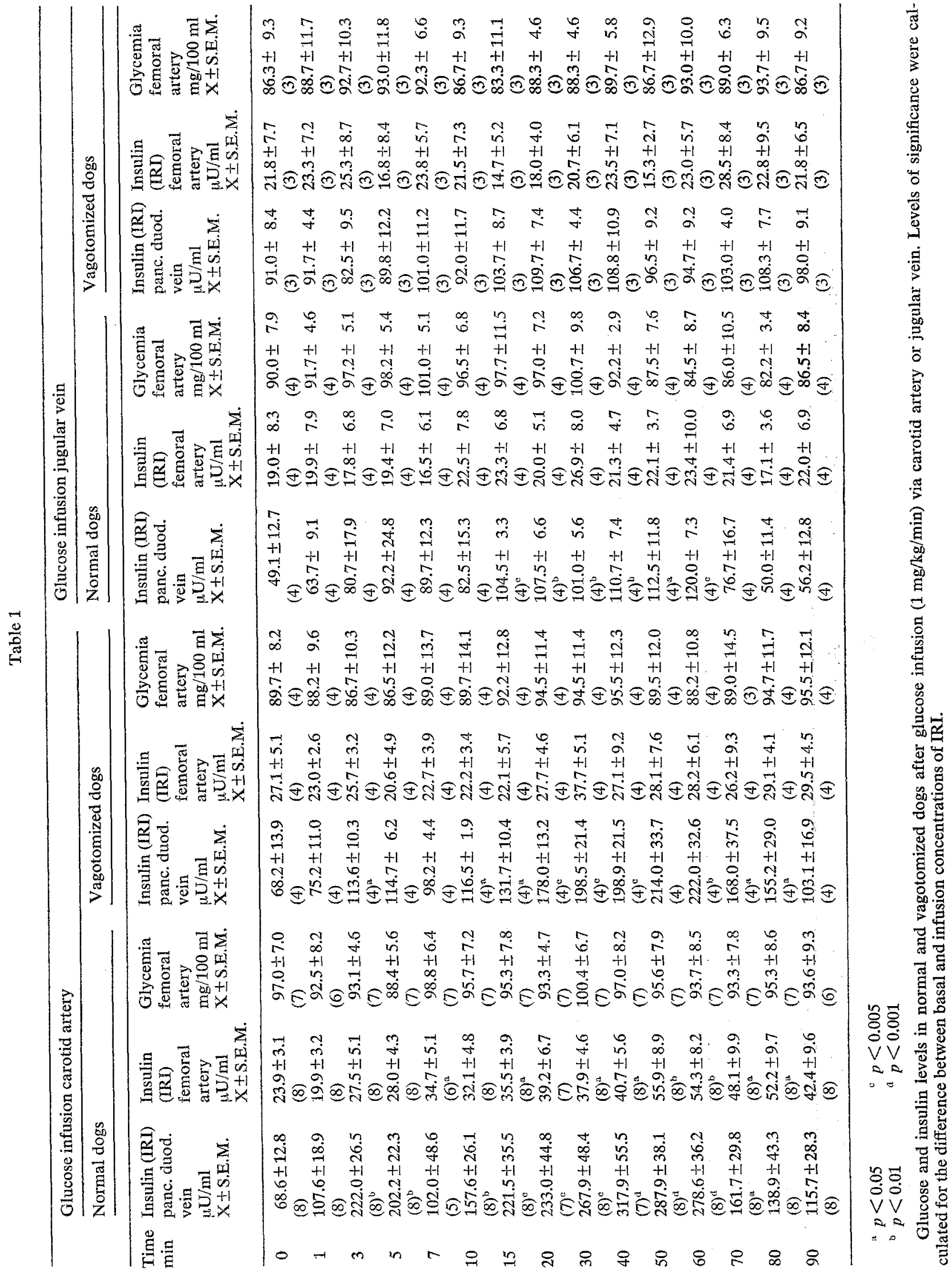




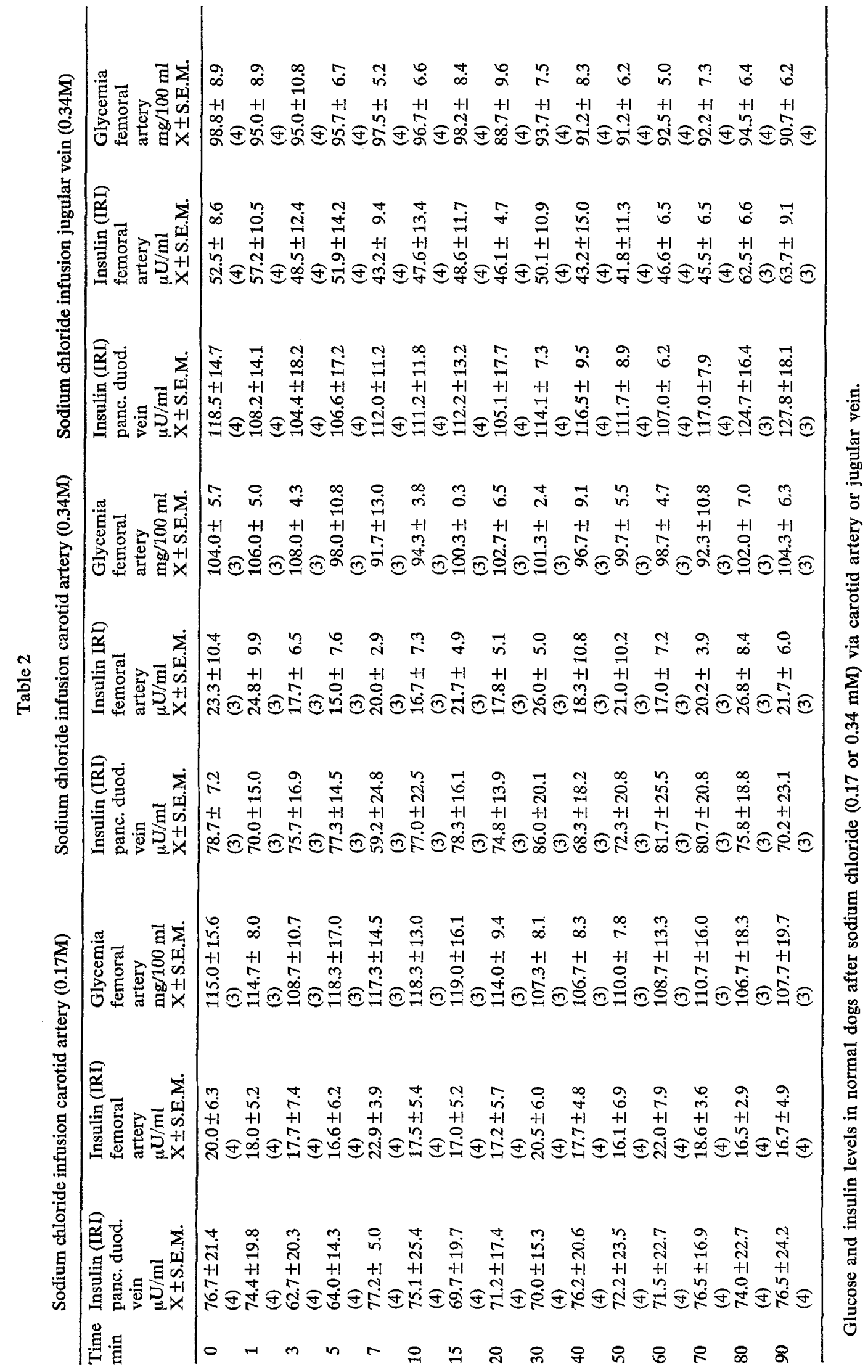


brain, but did not eliminate it. This would suggest that other mechanisms, besides the vagus nerve, are probably involved in the observed response.

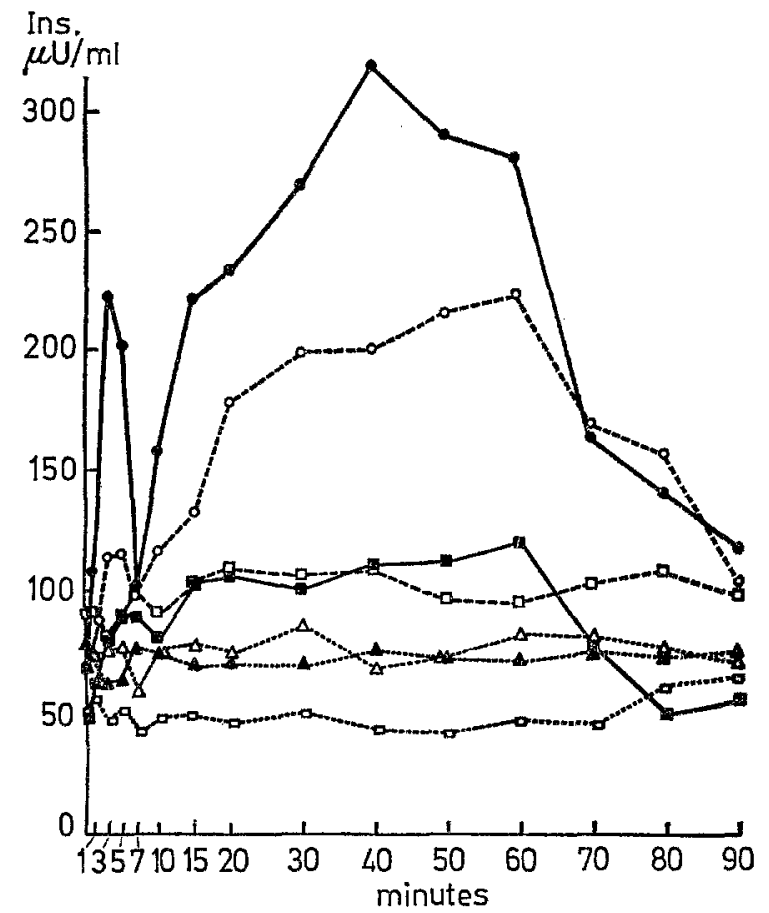

Fig. 1. Insulin levels in the pancreaticoduodenal vein after glucose or sodium chloride infusion via the carotid artery or the jugular vein

Glucose and Sodium Chloride Infusion Carotid Artery

- Glucose in normal dogs

O--O--O Glucose in vagotomized dogs

$\triangle \cdots \triangle \cdots \triangle \mathrm{Na} C \mathrm{Cl} 0.34 \mathrm{mM}$ in normal Dogs

A....... $\mathrm{Na} \mathrm{Cl} 0.17 \mathrm{mM}$ in normal dogs

Glucose and Sodium Chloride Infusion Jugular Vein

-1- Glucose in normal dogs

$\square--\square--\square$ Glucose in vagotomized dogs

$\square . . \square . \square \mathrm{Na} \mathrm{Cl} 0.34 \mathrm{mM}$ in normal dogs

Previous reports demonstrate that the ventrolateral hypothalamus secretes a humoral factor which provokes insulin secretion $[11,12,15]$. It has also been shown that local infusion of glucose to the ventro medial hypothalamus, provokes on augmentation in the rate of discharge of some neurones, suggesting the existence of glucose sensitive neurones [18]. It could be speculated that the arrival of glucose at the brain could provoke insulin secretion by at least two different mechanisms; one mechanism involving the vagus nerves, as has been demonstrated in the present investigation and the second one could be the secretion of a humoral factor. The existence of this humoral response to the arrival of glucose would explain why vagotomy was not capable of eliminating the insulin response to the central infusion of glucose.
The results obtained with the infusion of glucose via the jugular vein, in normal and vagotomized dogs deserve a separate comment. In the normal dogs, although insulin secretion did not reach the levels observed when glucose was infused via the carotid artery, it showed a mild but maintained increase in insulin output from $15 \mathrm{~min}$ after the infusion was started until the end of infusion, when it dropped to basal levels. On the contrary, the infusion of glucose via jugular vein in vagotomized dogs did not elicit any pancreatic response, clearly demonstrating that systemic infusion of glucose, at the dose employed acts as a stimulus for insulin secretion only when the vagus nerves are intact.

A possible explanation for this phenomenon is that vagotomy could provoke trophic alterations of the B-cells, causing a diminution in their sensitivity to glucose. Another hypothesis is that the response observed in the normal dogs, to the systemic glucose load, was mainly a vagal reflex, suggesting that the central nervous receptors for glucose have a lower glucose threshold than the B-cells. The fact that jugular infusion of glucose to normal dogs, at the dose employed, provoked insulin secretion without changes in systemic blood sugar level, deserves comment. This behavior can be explained assuming that the cephalic glucoreceptors are very sensitive and detect smaller changes in blood sugar levels than our method for blood sugar determination.

Further studies are being carried out in our laboratory to clarify the physiological role played by the neuroendocrine mechanism for insulin secretion suggested by this investigation.

Acknowledgements. Supported by grant $2305 \mathrm{c} / 73$ from the Consejo Nacional de Investigaciones Científicas y Técnicas and by grant from the University of Buenos Aires. The authors wish to thank for the excellent technical assistance of Miss Irene Villarreal.

\section{References}

1. Benson, B.: Insulin sensitivity and adrenocortical function in guinea-pigs with hypothalamic lesion. Acta. endocr. (Kbh), 53, 663-672 (1966)

2. Bernard, C.: Comp. Rend. Soc. Biol. 1, 60 (1849)

3. Brodoff, B.: Kogan, A., Slotnik, B., Hagedoon, J.: The effect of hypothalamic lesion in the sand rat maintained on a. high fat diet. Diabetologia 7, 59-67 (1971)

4. Cantee, R.: Wise, B., Goldfien, A., Gullixon, K., Fisher N., Gannong, W.: Neural pathways mediating the increase in adrenal medullary secretion produced by hypoglycemia. Proc. Soc. exp. Biol. 114, 10-13 (1963)

5. Charbon, G.: The influence of vagus nerves on the blood sugar level. Acta physiol. Pharmacol. 10, 119-135 (1961)

6. Dupré, J.: Regulation of the secretions of the pancreas. Ann. Rev. Med. 21, 299-310 (1970) 
7. Foglia, V. G.: Basabe, J. C., Chieri, R. A.: Evolution of diabetes after early testosterone treatment in rats. Diabetologia 5, 258-259 (1969)

8. Frohman, L., Ezdinli, E., Jand, R.: Effect of vagotomy and vagal stimulation on insulin secretion. Diabetes 16, 443-448 (1967)

9. Gayet, R., Guilaumnie, M.: La régulation de la sécrétion interne pancréatique par un processus humoral, demonstrée par des transplantations de pancréas. Expériences sur des animaux normaux. Compt. Rend. Soc. Biol. 97, $1613-1614$ (1927)

10. Herbert, V., Lau, K.; Gottlieb, S., Bleicher, S.: Coated charcoal immunoassay of insulin. J. clin. Endocrinol. 25, 1375-1384 (1965)

11. Hill, D., Mok, C., Cadell, T., Crowne, D.: Martin J.: Hypothalamic control of insulin secretion in monkeys. Excerpta Medica I.C.S. 280, 66 (1973)

12. Horward, N., Martin, J., Mok, C.: Mode of action of a hypothalamic islet-stimulating factor in man. Excerpta Medica I.C.S. 280, 66 (1973)

13. Houssay, B., Lewis, J., Foglia, V. G.: Influence de l'enervation sur les variations de la glycémie produites par l'injection de glucose. Campt. Rend. Soc. Biol. 100, 144 145 (1929)

14. Kaneto, A., Kosaka, K., Nakao, K.: Effects of stimulation of the vagus nerve on insulin secretion. Endocrinology, 80, $530-535$ (1967)

15. Martin, J., Mok, C., Hill, D., Crowne, D.: A hypothalamic islet-stimulating factor. Excerpta Medica. I.C.S. 280, 67 (1973)

16. Nelson, N.: A photometric adaptations of the Somogy method for the determination of glucose. J. biol. Chem. 153, 375-380 (1944)

17. Nelson, N., Bleckard, W., Cochiara, J., Sabat, J.: Influence of the vagues nerves on pancreatic insulin secretion. Diabetes 16, 852-857 (1967)

18. Oomura, Y., Ono, T., Ooyama, H., Wayner, M. J.: Glucose and osmosensitive neurones of the rat hypothalamus. Nature 222, 282-284 (1969)

19. Porte, D. (Jr.), Girardier, L., Seydoux, J.: Kanazawa, Y., Posternak, J.: Neural regulation of insulin secretion in the dog. J. clin. Invest. 52, 210-214 (1973)

20. Szabo, O., Szabo, A.: Evidence for an insulin-sensitive receptor in the central nervous system. Amer. J. Physiol. 223, 1319-1353 (1972)

21. Toivola, P., Gale, C., Goodner, C., Werrbach, J.: Central $\alpha$ adrenergic regulation of growth hormone and insulin. Hormone Research 3, 193-213 (1972)

22. Trifaro, J. M., Mikulic, E., Foglia, V. G.: Influencia de las lesiones hipotalámicas sobre el metabolismo de los hidratos de carbono. Rev. Soc. argent. Biol. 41, 86-91 (1965)

Dr. R. A. Chieri

Institute of Physiology

Buenos Airos Medical School

Buenos Aires

Argentinia 